Document downloaded from:

http://hdl.handle.net/10251/135018

This paper must be cited as:

Llorca Garcia, C.; Moreno, AT.; García García, A. (2016). Modelling vehicles acceleration during overtaking manoeuvres. IET Intelligent Transport Systems. 10(3):206-215. https://doi.org/10.1049/iet-its.2015.0035

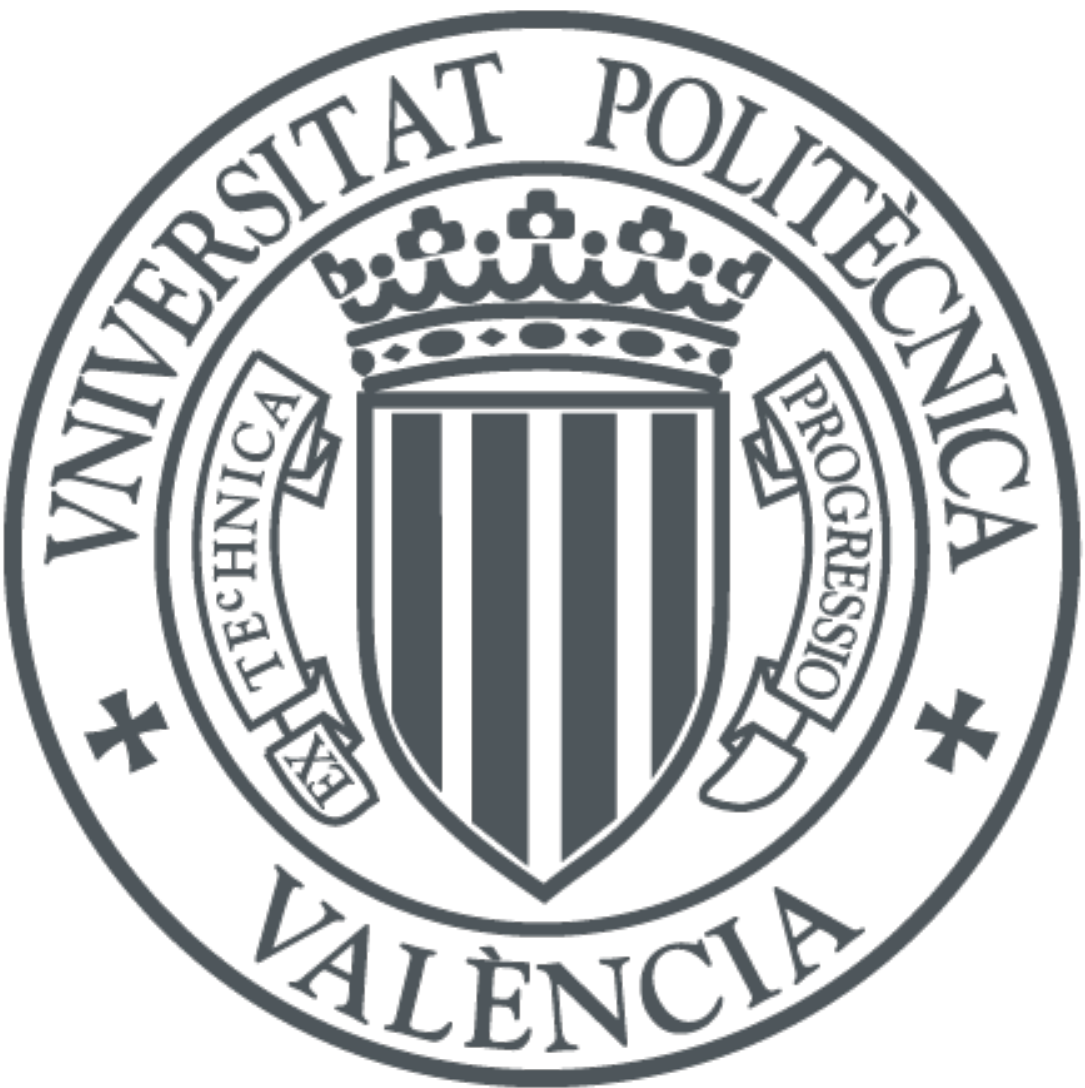

The final publication is available at

https://doi.org/10.1049/iet-its.2015.0035

Copyright Institution of Electrical Engineers

Additional Information 


\title{
Modelling vehicles acceleration during overtaking manoeuvres
}

\author{
Carlos Llorca \\ $\mathrm{PhD}$, Research assistant \\ Highway Engineering Research Group \\ Universitat Politècnica de València \\ Camino de Vera s/n 46022, Valencia (Spain) \\ +34 963877374 \\ carlloga@cam.upv.es \\ Ana Tsui Moreno \\ $\mathrm{PhD}$, Research assistant Highway Engineering Research Group \\ Universitat Politècnica de València \\ anmoch@cam.upv.es \\ Alfredo Garcia \\ Professor \\ Highway Engineering Research Group \\ Universitat Politècnica de València \\ agarciag@tra.upv.es
}

Keywords: two-lane rural road, overtaking sight distance, assistance system, microsimulation 


\section{Abstract}

25 Overtaking manoeuvre is a key issue for two-lane rural roads. These roads should provide suffi26 cient overtaking sight distance at certain locations to allow faster vehicles to pass slower ones. However, overtaking requires occupying the opposing lane, which represents a serious safety concern. Severity of overtaking related crashes is very high, compared to other manoeuvres. The development of Advanced Driver Assistance Systems (ADAS) for overtaking is being a complex task. Only few systems have been developed, but are not still in use. This research incorporated accurate data of real manoeuvres to improve the knowledge of the phenomenon. The trajectory of the overtaking vehicles on the left lane was observed. An instrumented vehicle measured the overtaking time and distance, the abreast position, and the initial and final speed of 180 drivers that passed it during a field experiment. Six different kinematic models (such as uniform acceleration or linear variation of acceleration) were calibrated. Generally, drivers started to accelerate before changing to the opposing lane. These models may be applied to ADAS, to estimate overtaking sight distance and to improve microsimulation models. 


\section{Introduction and background}

On two-lane rural roads, vehicles travelling at slower speeds cause delays to faster vehicles. Overtaking manoeuvres allow faster drivers to travel at their own desired speed, hence minimizing these delays. However, any overtaking manoeuvre requires to occupy the opposing lane to pass a slower vehicle. Therefore, the risk of collision with the opposing traffic affects both operation and safety.

The severity of accidents related to overtaking manoeuvres is usually higher than in other manoeuvres [1]. To complete an overtaking manoeuvre, the overtaking vehicle must increase its speed in order to pass a slower vehicle and return to the right lane. At the same time, an opposing vehicle could be approaching at a relatively high speed. The potential collision risk during the time the left lane is occupied makes driving behaviour different from other conditions, such as freeflow or following situations. To ensure road safety, overtaking is only allowed in the zones where available sight distance is higher than the required Overtaking Sight Distance (OSD). OSD is defined as the distance required to complete an overtaking manoeuvre when an opposing vehicle is approaching. OSD has been traditionally estimated using different overtaking manoeuvre models. The assumptions of those models, especially in relation to the overtaking vehicle acceleration and its variation, vary significantly and are not verified with field data. The knowledge of the values of the acceleration of the overtaking vehicle, as well as they possible variation during the manoeuvre, is one of the key issues in determining OSD.

Drivers make overtaking decisions according to their own behaviour and experience, as well as to road and traffic perception. According to Gray et al. [2], decisions during overtaking are based on drivers' perception of distance and time to collision with the oncoming traffic. They conclude that drivers tend to make more errors when their decisions are based only on the distance, after a driving simulator experiment with only 18 drivers. However, the estimation of the speed of opposing vehicles is extremely difficult, because of the very low rate of expansion of objects located so far from the observer. Additionally, Basilio et al. [3] and Morice et al. [4] proposed an overtaking decision model based on the overtaking ability affordance, defined as the quotient between the minimum speed required to overtake and the maximum speed of the vehicle at that time, depending on the vehicle performance. After a driving simulator experiment with only 16 drivers, they evidenced that drivers accurately perceived whether a lead vehicle can be safely overtaken, since overtaking attempt decreased with the real possibility to overtake. Alternatively, Farah et al. [5] modelled risk during overtaking maneuvers, by predicting Time To Collision (TTC) based on a driving simulator experiment with up to 100 drivers.

Driving simulator experiments confirmed the fact that overtaking manoeuvre is one of the most difficult ones. The use of driving simulator might limit the validity of findings, as risk taken by drivers depends on their immersion in the virtual world during the experiment, and the detection of opposing vehicles which at long distances is complicated, due to the limited resolution of screens. Besides, driving simulator usually only accounts for a very limited (or null) variability of acceleration capabilities of vehicles, because only one type [3] or two types [4] of vehicle are implemented. Consequently, a field study is solely able to study drivers' behaviour across a wide range of vehicles in real conditions.

\subsection{Overtaking models}

In some cases, speed of overtaking vehicle was assumed to be uniform during the left lane occupation time [6], although an acceleration stage was identified before occupying the left lane. This uniform speed model proposed an average acceleration rate of $0.62 \mathrm{~m} / \mathrm{s}^{2}$. Other models have used more complex kinematic equations, in order to describe overtaking vehicle trajectories [7][10]. Those usually suggested the existence of a critical point. After the critical point, it is safer to 
complete the overtaking manoeuvre rather than to abort it, because the time and distance requirements for this are lower. According to these models, the overtaking vehicle accelerates at a constant rate until the critical position and after that position; speed is constant and equal to the design speed. Alternative formulations were: uniform acceleration models [11] uniform acceleration until a target speed [12], or models based on a variable acceleration that decreased linearly as speed increased [13].

On the other hand, some authors accounted uncertainty in the overtaking process using reliability analysis or simulation techniques. These statistical tools could account the variability of input parameters and provide a probabilistic formulation for overtaking sight distance. Sparks et al. [14] used Glennon's and Liebermann's models incorporating statistical distributions of input parameters. Hanley and Forkenbrok [15] performed a simulation with previous OSD models, incorporating random distributions of input parameters, too. El Khoury and Hoberika [16] proposed a Monte Carlo simulation to evaluate risk level of OSD Glennon's model. The statistical distributions of acceleration rates were obtained from previous research works, although they were not related to overtaking manoeuvre studies. El Bassiouni and Sayed [17] developed a reliability analysis to compare AASHTO OSD model [6] with driving simulator data. However, the assumptions of that model remained unverified.

Other studies have used data of driving simulator experiments to analyse the acceleration of overtaking vehicles. Jenkins and Rilett [18] characterized the distribution of time spent accelerating for a sample of 96 manoeuvres. It was observed that on average the acceleration time was $13.3 \mathrm{~s}$, being the average overtaking time up to $20,0 \mathrm{~s}$, clearly double as most of field data, according to the authors. Besides, the acceleration capabilities of the simulated vehicles were uniform for all drivers. Rakha et al. [19] collected data of acceleration rates of different passenger cars performing an experiment under controlled conditions. The relationships between acceleration rates and speed were determined. The experiment was based on an acceleration movement starting at $0 \mathrm{~km} / \mathrm{h}$. Therefore, this results cannot be directly applied to overtaking manoeuvres, since acceleration rates can be different depending on the speed the manoeuvre starts and on driver reaction to a potential risky situation.

Some field studies [20], [21] recorded overtaking manoeuvres in order to calibrate the 2001 AASTHO model parameters using experimental data. However, they frequently did not verify assumptions of those models either (such as the fact that acceleration was uniform until reaching the design speed). Others authors [22], [23] have used instrumented vehicles to analyse the overtaking process on two-lane rural roads. Carlson et al. [22] described the evolution of overtaking vehicle speed, showing an initial acceleration stage followed by a second stage (after the abreast position) where acceleration was lower. However, Carlson et al. did not try to calibrate any acceleration model, and the distances to the overtaking vehicle were obtained from video data. Besides, they did not measure instant speed values at the start and the beginning of the manoeuvre.

\subsection{Assistance systems}

A further step after the prediction of the required OSD is the development of Advanced Driver Assistance Systems (ADAS). The benefits for ADAS may improve drivers' judgement errors, but they are not as common in overtaking as in other manoeuvres, such as lane changing or carfollowing. In fact, there are only few prototypes without real implementation.

As expressed by Morice et al. [4], ADAS for overtaking should be calibrated to be effective. It means that they should be coherent with drivers' behaviour. Therefore, individuals would agree with the system.

The effectiveness of ADAS has been already tested using microsimulation model RuTSim [24]. Those authors analysed safety benefits of an assistance system to warn drivers that were accepting an opposing gap too small. Either the effect on road safety (measured by the Time to Collision - TTC - with the opposing vehicle) or the effect on traffic operation (Average Travel Speed - ATS - and delay) were limited. In absence of accurate data of overtaking manoeuvres, the authors 
used several thresholds for TTC (equal to left lane occupation time plus a safety margin) ranging from 8 to $14 \mathrm{~s}$. One of the main shortcomings of the proposed system is that the overtaking threshold were pre-programmed and do not depend on the current conditions.

A different study conducted by Milanés et al. focused on the experimental simulation of assistance systems under controlled conditions [25]. The system depended on stereo vision to detect the preceding vehicle and to activate the automated overtaking system. Longitudinal and lateral controllers were tested in an experiment where the impeding vehicle was travelling at very low speed. The presence of opposing traffic was not considered.

Isermann et al. [26] proposed an assistance system to warn driver of dangerous overtaking manoeuvres, because of the presence of opposing vehicles. The system would detect opposing vehicles when an overtaking manoeuvre has been initiated. Dangerous situations would result in a warning signal (to encourage the driver to abort) or even in an emergency braking. Both overtaking model and safety margins were not calibrated, though. Petrov and Nashashibi [27] developed a mathematical model and an adaptive controller for automated overtaking. The system was tested using driving simulation, but it has not been compared with real data.

Lastly, Lowenau et al. [28] developed a overtaking assistance system based on the characterization of the previous driving behaviour (speed, acceleration, etc.) and geographical information provided by a GPS tracker. This system would encourage or discourage drivers to pass depending on the road and on their behaviour. However, this system does not provide information on the opposing traffic presence.

As can be seen, most of the previous studies propose potential solutions to develop ADAS for overtaking. Most of them were based only on numerical simulations [24], [26], or driving simulator studies [27] and were not programmed after observing the real behaviour. Driving data in real conditions is still needed to produce ADAS on the conditions that drivers may encounter in the real world. Those systems that can avoid drivers' errors require determining the thresholds for safe overtaking, in terms of distance travelled on the left lane and subsequently, acceleration rates. In absence of an accurate estimation of this variable, it is not possible to take into account the real risk of collision with opposing traffic.

\subsection{Research motivation}

The effects of overtaking manoeuvre on road safety and road operation motivate the improvement of design and marking of two-lane rural roads and the development of ADAS. With this purpose, the estimation of the duration and distance of occupation of the opposing lane is needed. The knowledge of the acceleration rates of overtaking drivers is one of the most significant variables that input it. The characterization of the distribution of that acceleration must depend on field data, instead on driving simulation, because off the actual variability of vehicle capacities.

As previously commented, the calibration of ADAS that reproduces drivers' behaviour is the only way to ensure they are effective. Drivers' should agree with the ADAS recommendations, so they should represent how drivers perform safe manoeuvres without having such assistance systems. Previous research did not provide sufficient level of detail, or was based on driving simulation instead real data and, consequently, development of ADAS is still a challenge.

\section{Objectives}

The aim of this study was to calibrate overtaking acceleration models using field data collected on two-lane rural roads, in order to provide a reliable estimation of the left lane occupation time and of the evolution of the speed along it. This included:

- An improved data collection method to collect data of overtaking manoeuvres under naturalistic conditions. 
- Calibration of different kinematic models based on the assumptions from previous research studies. In addition, proposal of new models so that some of those assumptions would no longer be required.

\section{Methodology}

The proposed models were calibrated from observational data, collected with an instrumented vehicle.

\subsection{Field study}

In this research work, the methodology, analysis and conclusions were based on experimental data, which was collected using a recently developed methodology [29]-[31]. This method used an instrumented vehicle acting as slow impeding vehicle, which was overtaken by other drivers during the experiment. The vehicle collected the data of those drivers and the manoeuvres they performed. Therefore, acceleration capabilities varied for each tested driver.

With respect of previous authors that used also instrumented vehicles [22], the proposed methodology improved the measurement of the distance to the overtaking vehicle by using laser rangefinders. Besides, it allowed a more detailed information of the passing driver, including gender and estimated age, although these data were not used in this paper.

\subsubsection{Equipment}

The instrumented vehicle travelled along five different two-lane rural road segments (of various characteristics, as expressed below in Table 1) at a fixed, slightly reduced, speed with respect of the operating speed of the road. If the desired speed of the other vehicles was higher, they followed the instrumented vehicle and finally passed it when they found an available gap.

This vehicle was equipped with four Racelogic VBOX 720x576 pixels resolution digital video cameras covering the whole trajectory of an overtaking vehicle (rear, left and front side - note that the experiment was carried out under right hand driving). In addition to this, two LTI True Senses S200 laser rangefinders measured the distance between the instrumented vehicle and every vehicle located behind and in front of it, at a $12.5 \mathrm{~Hz}$ frequency. Since distance measurement was continuous, instant speeds of those vehicles were also obtained. Rear laser rangefinder was placed at the rear bumper. The front distance measurements were obtained with a laser gun controlled by the co-driver. On the other hand, a Racelogic VBOX $10 \mathrm{~Hz}$ GPS tracker registered the position and speed of the instrumented vehicle at any time.

Equipment was adequately small that other drivers could not easily detected its presence. In addition to this, the vehicle drove at a uniform speed Vi, different for each segment (as shown in Table 1). It was selected within normal impeding vehicle speed range, which was obtained from external observations from a previous research study [29].

\subsubsection{Overtaking manoeuvre variables}

Although video recordings provided a continuous observation of the overtaking phenomenon, the estimation of the overtaking vehicle trajectory was made from three point measurements, where position of overtaking vehicle was measured accurately (see in detail in Figure 1):

- Time $(t 1)$ at the starting time of overtaking manoeuvre (when overtaking vehicle left front wheel crosses the centreline), headway between overtaking and instrumented vehicle (h1) and relative speed ( $d V p 1)$.

- Time (t2) at the abreast location (when front bumper of both overtaking and impeding vehicle are at the same point).

- Time ( $t 3$ ) at the ending time of overtaking manoeuvre (when overtaking vehicle left rear wheel crosses the centreline), headway between overtaking and instrumented vehicle (h3) and relative speed (dVp3). 
$t=t 1$ : overtaking vehicle first encroaches left lane

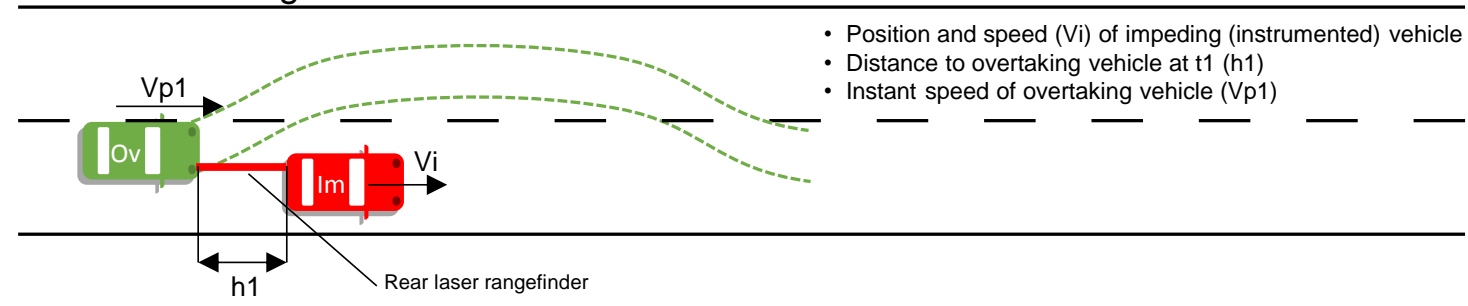

$\mathrm{t}=\mathrm{t} 2$ : overtaking and impeding vehicle are abreast

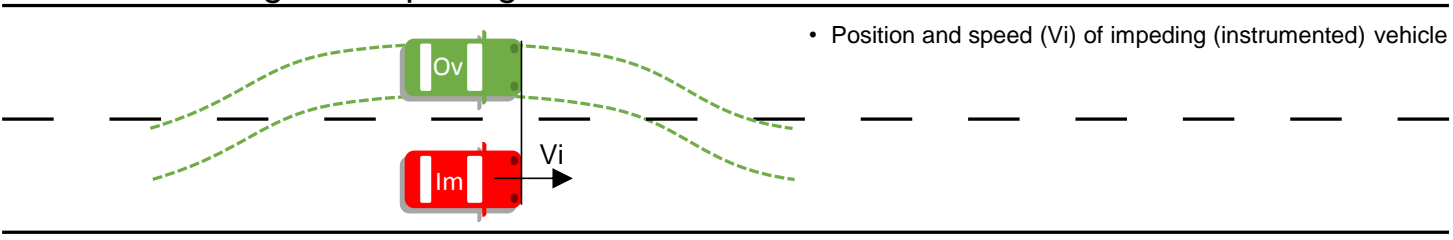

$\mathrm{t}=\mathrm{t} 3$ : overtaking vehicle returns to right lane

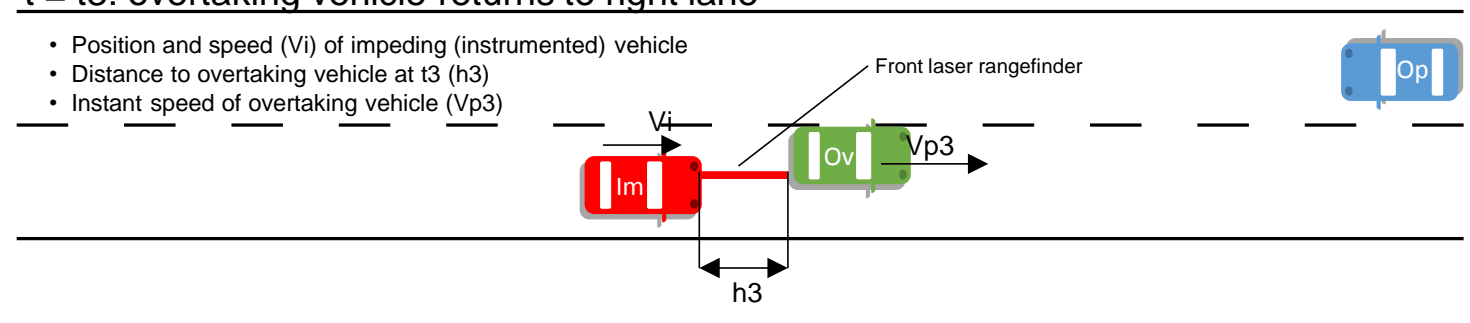

$t=t 4$ : overtaking vehicle crosses with opposing vehicle

t1 to t3: left lane occupation

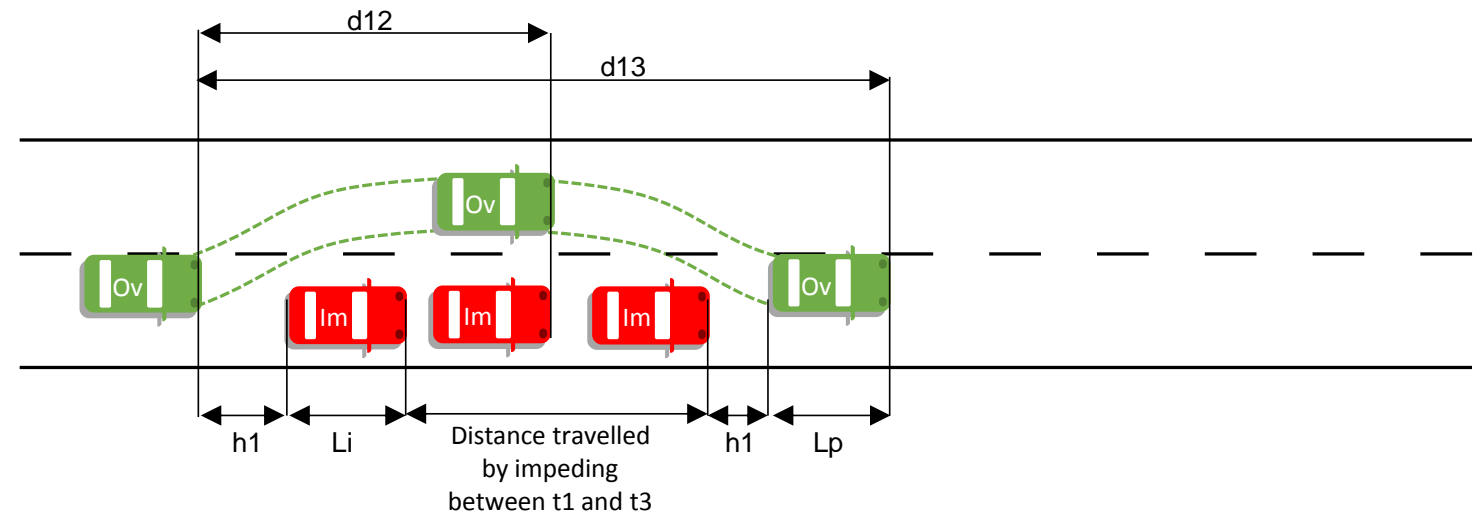

Figure 1. Overtaking manoeuvre phases and variables (Ov: overtaking vehicle, Im: impeding vehicle/instrumented vehicle and Op: opposing vehicle)

The values of $t 1, t 2$ and $t 3$ were identified by viewing video files of each manoeuvre. Distance between overtaking and impeding vehicle were obtained using the rear laser rangefinder and front laser gun, respectively. Distances travelled along the one-second intervals centred at $t 1$ and $t 3$ were considered for the relative speed calculation in order to reduce possible measurement errors. 
In addition to this, GPS data provided the trajectory of the instrumented impeding vehicle at a 10 $\mathrm{Hz}$ frequency. Speed of the impeding vehicle $\mathrm{Vi}$ was added to the relative speeds to obtain the absolute overtaking vehicle speeds. The distance travelled between $t 1$ and $t 2$ (interval $t 12$ ) was named $d 12$. The distance travelled from $t 1$ to $t 3$ (interval $t 13$ ) was named $d 13$.

Lastly, the time when overtaking and opposing vehicle crossed each other was called $t 4$. The time interval $t 34$ (equal to $t 4-t 3$ ) measured the safety margin until the potential collision with the opposing car (Time to Collision).

Additional data were also collected from video images and vehicle passenger annotations. The following variables were registered:

- Type of overtaking vehicle: car, truck.

- Starting mode: if the overtaking vehicle starts the manoeuvre after following the impeding at the same speed, the manoeuvre is accelerative, if the overtaking vehicles does not reduce the speed prior to overtake, the manoeuvre is flying.

Since all the data was obtained using this methodology, it was not possible to know the maximum speed and acceleration that can develop every overtaking vehicle. These data would depend on the power/weight ratio and was not available, due to the naturalistic characteristics of the experiment, which avoided any intervention during the observations.

\subsubsection{Data collection}

Using the described methodology, 265 overtaking manoeuvres were recorded on five two-lane rural road segments.

A total of 85 were discarded due to one or more of the following reasons:

- Overtaking vehicle was a truck (14 manoeuvres).

- More than one impeding vehicle was passed (40 multiple manoeuvres).

- In accelerative manoeuvres, either front, or rear or both laser distance measurements were missing or not valid (52 manoeuvres).

In consequence, model calibration was made using only manoeuvres involving one overtaking passenger car and one impeding vehicle (the instrumented vehicle); and with plausible laser measurements at $t 1$ and $t 3$. The selected sample was 151 accelerative overtaking manoeuvres and 29 flying overtaking manoeuvres.

No aborted manoeuvres were registered during data collection. Therefore, only completed overtaking manoeuvres were modelled.

Table 1 summarizes characteristics of road segments and overtaking zones.

\begin{tabular}{ccccc}
\hline Road ID & Date & $\begin{array}{c}\text { Design speed } \\
(\mathbf{k m} / \mathbf{h})\end{array}$ & $\begin{array}{c}\text { Number of manoeu- } \\
\text { vres }\end{array}$ & $\begin{array}{c}\text { Impeding vehicle } \\
\text { speed (Vi, in } \mathbf{~ k m} / \mathbf{h})\end{array}$ \\
\hline $\mathbf{N}-225$ & $06 / 02 / 2012$ & 100 & 62 & 80 \\
\hline CV-415 & $13 / 09 / 2012$ & 70 & 55 & 60 \\
\hline CV-415 & $08 / 11 / 2012$ & 70 & 30 & 60 \\
\hline CV-50 & $08 / 11 / 2012$ & 80 & 48 & 70 \\
\hline CV-405 & $20 / 11 / 2012$ & 70 & 70 & 60 \\
\hline
\end{tabular}

Table 1. Selected road segments

Table 2 shows recorded overtaking manoeuvre variables. First and second rows represent mean and standard deviation of each variable in columns, for accelerative passes. Third and fourth rows show the same for flying passes. 


\begin{tabular}{|c|c|c|c|c|c|c|c|c|c|c|c|}
\hline \multirow{2}{*}{\multicolumn{2}{|c|}{ Starting mode }} & \multicolumn{10}{|c|}{ Variable } \\
\hline & & \multirow{2}{*}{$\begin{array}{c}\begin{array}{c}d 12 \\
(\mathrm{~m})\end{array} \\
61.2 \\
\end{array}$} & \multirow{2}{*}{$\begin{array}{c}\begin{array}{c}d 13 \\
(\mathrm{~m})\end{array} \\
163.8\end{array}$} & \multirow{2}{*}{$\begin{array}{l}\begin{array}{l}t 12 \\
(\mathrm{~s})\end{array} \\
2.9\end{array}$} & \multirow{2}{*}{$\begin{array}{l}\begin{array}{l}t 13 \\
(\mathrm{~s})\end{array} \\
7.1 \\
\end{array}$} & \multirow{2}{*}{$\begin{array}{c}t 34 \\
(\mathrm{~s}) \\
4.6\end{array}$} & \multirow{2}{*}{$\begin{array}{c}\begin{array}{c}h 1 \\
(\mathrm{~m})\end{array} \\
7.5\end{array}$} & \multirow{2}{*}{$\begin{array}{c}\begin{array}{c}V p 1 \\
(\mathrm{~km} / \mathrm{h})\end{array} \\
71.1\end{array}$} & \multirow{2}{*}{$\begin{array}{c}\begin{array}{c}h 3 \\
(\mathrm{~m})\end{array} \\
21.2\end{array}$} & \multirow{2}{*}{$\begin{array}{c}\begin{array}{c}V p 3 \\
(\mathrm{~km} / \mathrm{h})\end{array} \\
88.8\end{array}$} & \multirow{2}{*}{$\begin{array}{c}\begin{array}{c}V i \\
(\mathrm{~km} / \mathrm{h})\end{array} \\
65.5\end{array}$} \\
\hline Accelera- & Mean & & & & & & & & & & \\
\hline 115) & SD & 19.0 & 42.0 & 0.9 & 1.8 & 2.0 & 3.7 & 10.4 & 8.2 & 11.1 & 8.3 \\
\hline \multirow{2}{*}{$\begin{array}{l}\text { Flying (N } \\
=29)\end{array}$} & Mean & 70.2 & 162.5 & 2.7 & 6.3 & $\mathrm{n} / \mathrm{a}$ & 27.8 & $\mathrm{n} / \mathrm{a}$ & 25.2 & $\mathrm{n} / \mathrm{a}$ & 64.3 \\
\hline & SD & 22.1 & 44.5 & 0.8 & 1.6 & $\mathrm{n} / \mathrm{a}$ & 14.2 & $\mathrm{n} / \mathrm{a}$ & 14.0 & $\mathrm{n} / \mathrm{a}$ & 8.4 \\
\hline
\end{tabular}

\section{$274 \quad 3.2 . \quad$ Models proposal}

The aim of this study was the calibration of several overtaking vehicle acceleration models using experimental data. The field study in this research made possible the measurement of more variables than any other previous studies. In the past, only some authors have recorded the entire trajectory of a passing vehicle. Llorca and Garcia [29] carried out a field study based on externalstatic cameras transforming video images into complete trajectories. The results were limited as this method was very time-consuming. Alternative methods based on instrumented vehicles [22] acting as impeding vehicles did not collect as many data points as the present study, especially because they did not use laser rangefinders.

Even using the proposed method, there is still a lack of information between the times $t 1$ and $t 2$, and $t 2$ and $t 3$. This justifies the procedure of fitting different models and compare the calibration errors among them, as will be explained later. Table 3 shows a list of models, starting with the simplest one (uniform overtaking vehicle speed) and following with more complex approaches. Most of recent existing OSD models in the literature have been included in Table 3. This include new model proposals, too. 


\begin{tabular}{|c|c|c|c|}
\hline Achronym & Model (references) & Equations & Parameters \\
\hline US & $\begin{array}{l}1 \text { Uniform speed } \\
{[6],[17],[20]}\end{array}$ & $\begin{array}{c}a=0 \\
V=V p m 13\end{array}$ & $\begin{array}{c}\text { a: acceleration rate } \\
\text { Vpm13: overtaking vehicle } \\
\text { average speed between } \mathrm{t} 1 \\
\text { and } \mathrm{t} 13\end{array}$ \\
\hline UA & $\begin{array}{c}2 \text { Uniform acceleration } \\
{[11]}\end{array}$ & $\begin{array}{l}a=a(\text { uniform }) \\
V=V p 1+a \cdot t\end{array}$ & $\begin{array}{l}\text { a: acceleration rate } \\
\text { Vp1: overtaking vehicle ini- } \\
\text { tial speed }\end{array}$ \\
\hline 2SUA & $\begin{array}{l}3 \text { Two-stage uniform } \\
\text { acceleration }\end{array}$ & $\begin{array}{c}\text { if } t<t 12: \\
a=a 12 \\
v=V p 1+a 12 \cdot t \\
\text { if } t>t 12: \\
a=a 23 \\
v=V p 1+a 1 \cdot t 12+a 2 \cdot(t \\
-t 12)\end{array}$ & $\begin{array}{l}\text { t12: time until the abreast } \\
\quad \text { position } \\
\text { a12: acceleration rate be- } \\
\text { fore abreast position } \\
\text { a23: acceleration rate after } \\
\quad \text { abreast position } \\
\text { Vp1: overtaking vehicle ini- } \\
\quad \text { tial speed }\end{array}$ \\
\hline UAFS & $\begin{array}{c}4 \text { Uniform acceleration } \\
\text { until reaching final } \\
\text { speed } \\
{[7],[8],[10],[12],[32]}\end{array}$ & $\begin{array}{c}\text { if } t<t f: \\
a=a \\
V=V p 1+a \cdot t \\
\text { if } t>t f \\
a=0 \\
V=V p 1+a \cdot t f\end{array}$ & $\begin{array}{l}\text { tf: ending time of the accel- } \\
\text { eration stage } \\
\text { a: acceleration rate } \\
\text { Vp1: overtaking vehicle ini- } \\
\text { tial speed }\end{array}$ \\
\hline LTA & $\begin{array}{l}5 \text { Variable acceleration } \\
\text { (linear time function) }\end{array}$ & $\begin{array}{c}a=m t+n \\
V=V p 1+m \cdot t^{2}+n \cdot t\end{array}$ & $\begin{array}{c}\text { a: acceleration rate } \\
m: \text { acceleration change per } \\
\text { time unit } \\
n: \text { initial acceleration at } \\
\text { time } 0 \\
\text { Vp1: overtaking vehicle ini- } \\
\text { tial speed }\end{array}$ \\
\hline LSA & $\begin{array}{l}\text { 6: Variable accelera- } \\
\text { tion (linear speed func- } \\
\text { tion) }\end{array}$ & $\begin{array}{c}a=m v+n \\
V=\frac{n+m \cdot V p 1}{m} \cdot e^{-m \cdot t}-\frac{n}{m}\end{array}$ & $\begin{array}{c}\text { a: acceleration rate } \\
m: \text { acceleration change per } \\
\text { speed unit } \\
n: \text { acceleration at speed = } \\
0 \\
\text { Vp1: overtaking vehicle ini- } \\
\text { tial speed }\end{array}$ \\
\hline
\end{tabular}




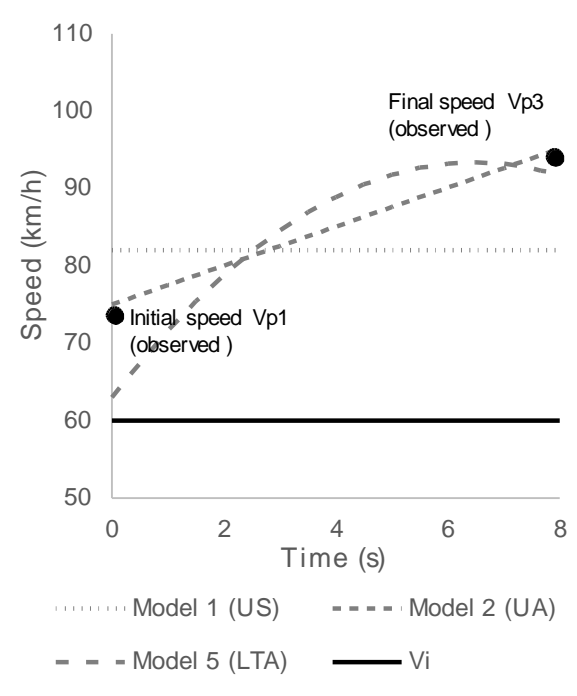

(a) Speed

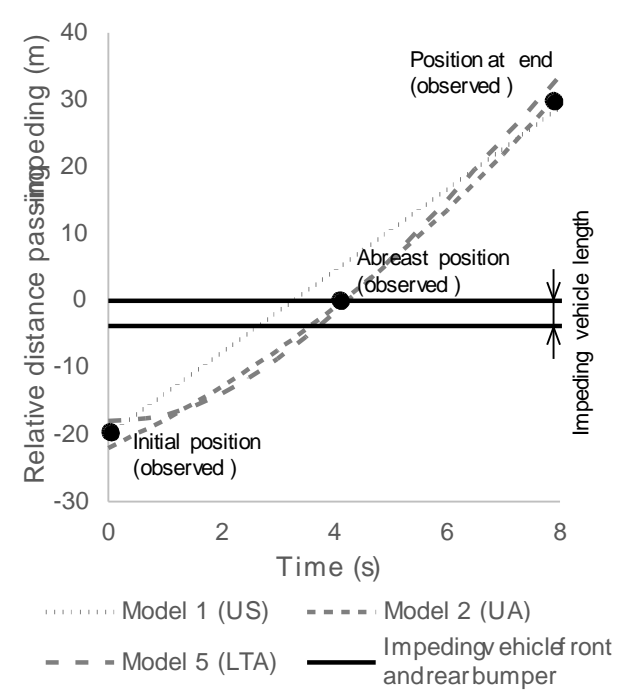

(b) Relative position

Figure 2 shows an example of the differences between three of the six alternative models (without scale). Black dots represented measured data points. The use of different models may affect the accuracy in the estimation of initial and final speeds (Figure 2a), and distance travelled at the abreast position and at the end of the overtaking manoeuvre (Figure $2 b$ ). As can be seen, the models do not fit the data exactly, but some of them are closer than other ones. This is the basis of the calibration and comparison of up to six models.

The real acceleration process depended on driver's decision and ability, as well as on vehicle performance. The presented models are alternative approaches to describe this process. The potential applications of this study (microsimulation models, probabilistic OSD standards) require the formulation of simple models, where the parameters are defined as random variables. Models were defined as a set of equations, which described the evolution of the overtaking vehicle along its left lane occupation time.

\subsection{Model calibration}

Due to overtaking variables randomness, the objective of calibration was to estimate the model parameters for each single overtaking manoeuvre. After that, a probability function of each parameter was estimated considering the entire sample. The calibration of models was carried out in two different groups. The first one included only accelerative manoeuvres, since they always involved a positive acceleration starting at a slow speed, near to impeding vehicle speed. A total of 151 overtaking manoeuvres were included in this group.

The second group corresponded to flying overtaking manoeuvres. In this case, overtaking vehicle trajectory was very different and starting speed was not necessary so close to impeding vehicle speed as in accelerative passes. On the other hand, during most flying overtaking manoeuvres, no rear distance measurement could be possible, since in those manoeuvres, the value of headway $h 1$ was significantly higher (an average of $27.8 \mathrm{~m}$ while it was $7.5 \mathrm{~m}$ in accelerative passes) or was out of the laser rangefinder measurement field. A total of 29 manoeuvres were included in the second group.

\subsubsection{Accelerative manoeuvres}

The objective of the calibration of the models of Table 3 was to estimate the value of model parameters, which determine the minimum deviation between estimated and observed overtaking vehicle trajectory. 
Parameters estimation was performed for each individual overtaking manoeuvre and after that, they were aggregated. For each model and each recorded overtaking manoeuvre the calibration was made by minimizing the function $F$ (Equation 1). This function is defined as a vector of four components. Each component is the relative error in the estimation of each of the overtaking manoeuvre variables.

$$
F\left(X_{i}, M_{i}\right)=\left\{\begin{array}{l}
\frac{d 13_{\text {model }}\left(M_{i}\right)-d 13_{\text {observed }}}{d 13_{\text {observed }}} \\
\frac{d 12_{\text {model }}\left(M_{i}\right)-d 12_{\text {observed }}}{d 12_{\text {observed }}} \\
\frac{V p 1_{\text {model }}\left(M_{i}\right)-V p 1_{\text {observed }}}{V p 1_{\text {observed }}} \\
\frac{V p 3_{\text {model }}\left(M_{i}\right)-V p 3_{\text {observed }}}{V p 3_{\text {observed }}}
\end{array}\right\}
$$

Where:

- $X i=(d 13$ observded, $d 12$ observed,Vp1observed,Vp3observed $)$ is a vector of the four observed dynamic variables for manoeuvre $i$.

- d13model,d12model, Vp1model and Vp3model are functions of $M_{i}$, according to the selected model, based on Table 3.

- $\quad M i=(m i 1, m i 2, \ldots m i K)$ is a vector of $K$ model parameters for manoeuvre $i$.

Each component of the function corresponded to the difference between the estimated and the observed value of the following variables: distance travelled until $t 3(d 13)$, distance travelled until $t 2$ (d12), speed at $t 1$ (Vp1) and speed at $t 3(\mathrm{Vp} 3)$. These components were divided by the observed value of each one. The reason of this was to give the same relative importance to all of them.

Since number of parameters (between one and three, depending on the model) was lower than number of available data, the equation $F=0$ (minimize the error) was solved using least square methods. Both linear and nonlinear least square procedures were applied, (depending on the linearity of model equations), using the Optimization Toolbox included in MATLAB software. The objective of these function was to minimize the terms of the function $F\left(X_{i}, M_{i}\right)$ according to the Equation 2.

$$
M_{i} / \min \left(f_{1}\left(X_{i}, M_{i}\right)^{2}+f_{2}\left(X_{i}, M_{i}\right)^{2}+f_{3}\left(X_{i}, M_{i}\right)^{2}+f_{4}\left(X_{i}, M_{i}\right)^{2}\right) \text { for } i=1 \text { to } N
$$

\section{Where:}

- $X i=(d 13$ observded, $d 12$ observed,Vp1observed,Vp3observed $)$ is a vector of the four observed kinematic variables for manoeuvre $i$.

- d13model,d12model, Vp1model and Vp3model are functions of $M_{i}$, according to the selected model, based on Table 3.

- $\quad M i=(m i 1, m i 2, \ldots m i K)$ is a vector of $K$ model parameters for manoeuvre $i$.

- $\quad N$ is the number of manoeuvres.

For each model, parameter probability distributions were analysed after aggregating all manoeuvres. Table 4 summarizes the probability distribution of each parameter as well as existing correlations between different parameters. In every case, the distribution fitting was checked using both Chi-Square and Kolmogorov-Smirnov tests. Correlations between model parameters have been analysed. Table 4 includes significant correlations (over 0.5 ) at the $95 \%$ confidence level. 


\begin{tabular}{|c|c|c|}
\hline Model & Parameters & $\begin{array}{l}\text { Distribution and values (mean } \pm S D \text { ) } \\
\text { Correlation coefficients }\end{array}$ \\
\hline 1 US: Uniform speed & Vpm13/Vi & Lognormal $(1.20 \pm 0.06)$ \\
\hline \multirow{3}{*}{2 UA: Uniform acceleration } & $V p 1 / V i$ & Lognormal $(1.10 \pm 0.05)$ \\
\hline & $a$ & Lognormal $(0.77 \pm 0.48)$ \\
\hline & correlations (coefficient) & not significant \\
\hline \multirow{4}{*}{$\begin{array}{l}3 \text { 2SUA: Two-stage uniform } \\
\text { acceleration }\end{array}$} & Vp1/Vi & Lognormal $(1.08 \pm 0.05)$ \\
\hline & a12 & Normal $(1.19 \pm 0.74)$ \\
\hline & a23 & Normal $(0.40 \pm 0.54)$ \\
\hline & correlations (coefficient) & a12 and a23 $(-0.57)$ \\
\hline \multirow{4}{*}{$\begin{array}{l}4 \text { UAFS: Uniform acceleration } \\
\text { until final speed }\end{array}$} & Vp1/Vi & Lognormal (1.08 \pm 0.04$)$ \\
\hline & $a$ & Lognormal (1.31 \pm 0.68$)$ \\
\hline & $t f$ & Normal $(4.31 \pm 1.73)$ \\
\hline & correlations (coefficient) & $\underline{\mathrm{a} \text { and } \mathrm{tf}(-0.66)}$ \\
\hline \multirow{4}{*}{$\begin{array}{l}5 \text { LTA: Variable acceleration } \\
\text { (linear time function) }\end{array}$} & $V p 1 / V i$ & Lognormal $(.08 \pm 0.05)$ \\
\hline & $m$ & Normal $(0.13 \pm 0.18)$ \\
\hline & $n$ & Normal $(1.15 \pm 0.75)$ \\
\hline & correlations (coefficient) & $\underline{m}$ and $n(-0.90)$ \\
\hline \multirow{4}{*}{$\begin{array}{l}6 \text { LSA: Variable acceleration } \\
\text { (linear speed function) }\end{array}$} & $V p 1 / V i$ & Normal $(1.08 \pm 0.05)$ \\
\hline & $m$ & Normal $(-0.19 \pm 0.29)$ \\
\hline & $n$ & Normal $(5.13 \pm 6.45)$ \\
\hline & correlations (coefficient) & $\mathrm{m}$ and $\mathrm{n}(-0.99)$ \\
\hline
\end{tabular}

Figure 3 represents the percent root mean squared error (RMSEj) for each calibration variable $\mathrm{j}$ and model. RMSE was calculated using the Equation 3.

$R M S E_{j}=\sqrt{\frac{1}{N} \sum_{i=1}^{N}\left(f_{i j}\right)^{2}}$

Where fij is the relative error of variable $j$ in the manoeuvre $i$, corresponding to a term of the function $f(X i, M i)$.

As can be seen, increasing model complexity, the estimation errors generally decrease, since models 3 (2SUA), 4 (UAFS) and 5 (LTA) had the lowest errors for each variable. In Figure 4, models are ranked according to the percentage of cases in which they are the best (and the second best) fitted model, according to the RMSE. It means, in example, that model 3 (2SUA) was the best model for $28 \%$ of the cases and was in the second place for $26 \%$. 


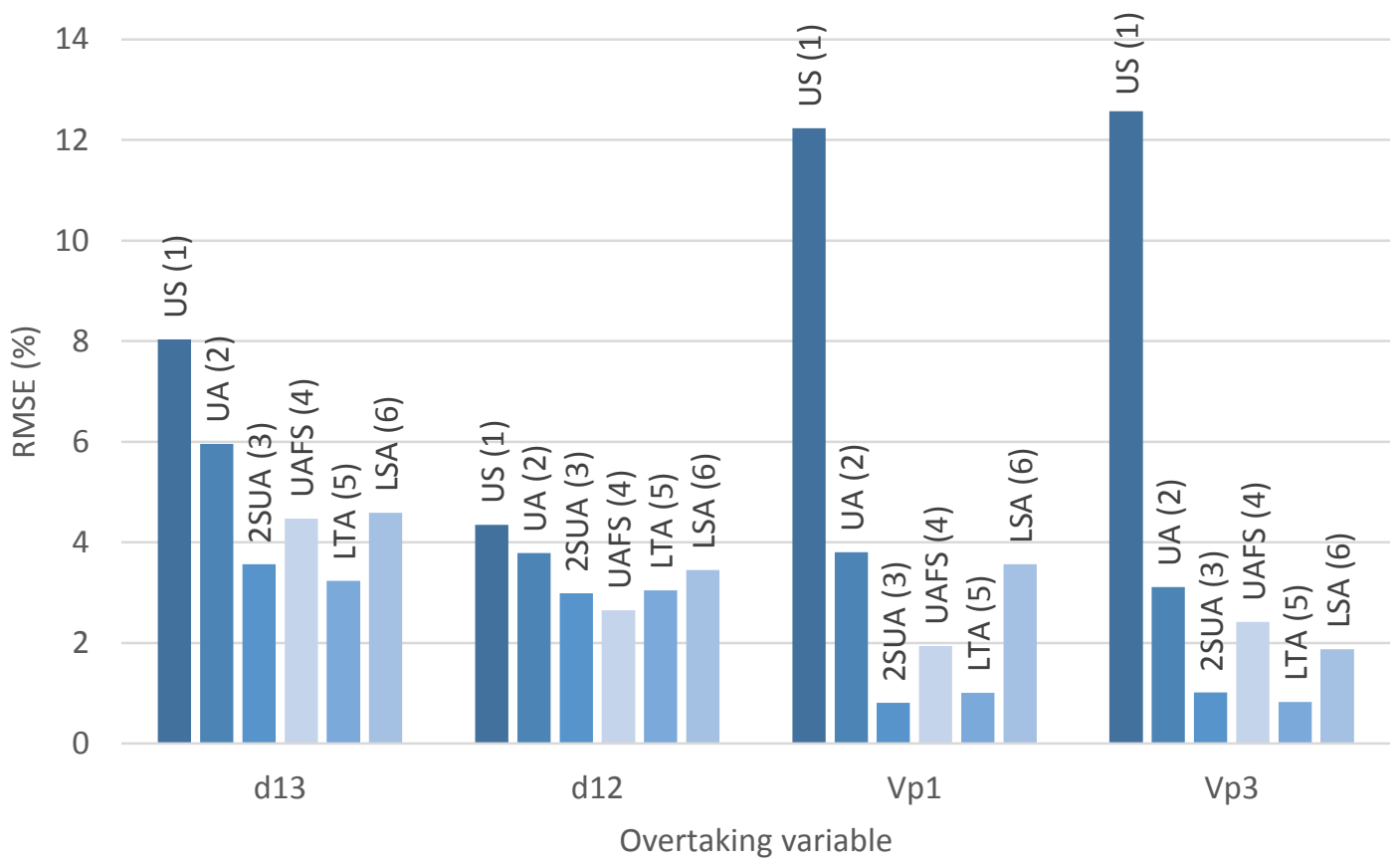

Figure 3. Root mean square error (percent) for each model and variable

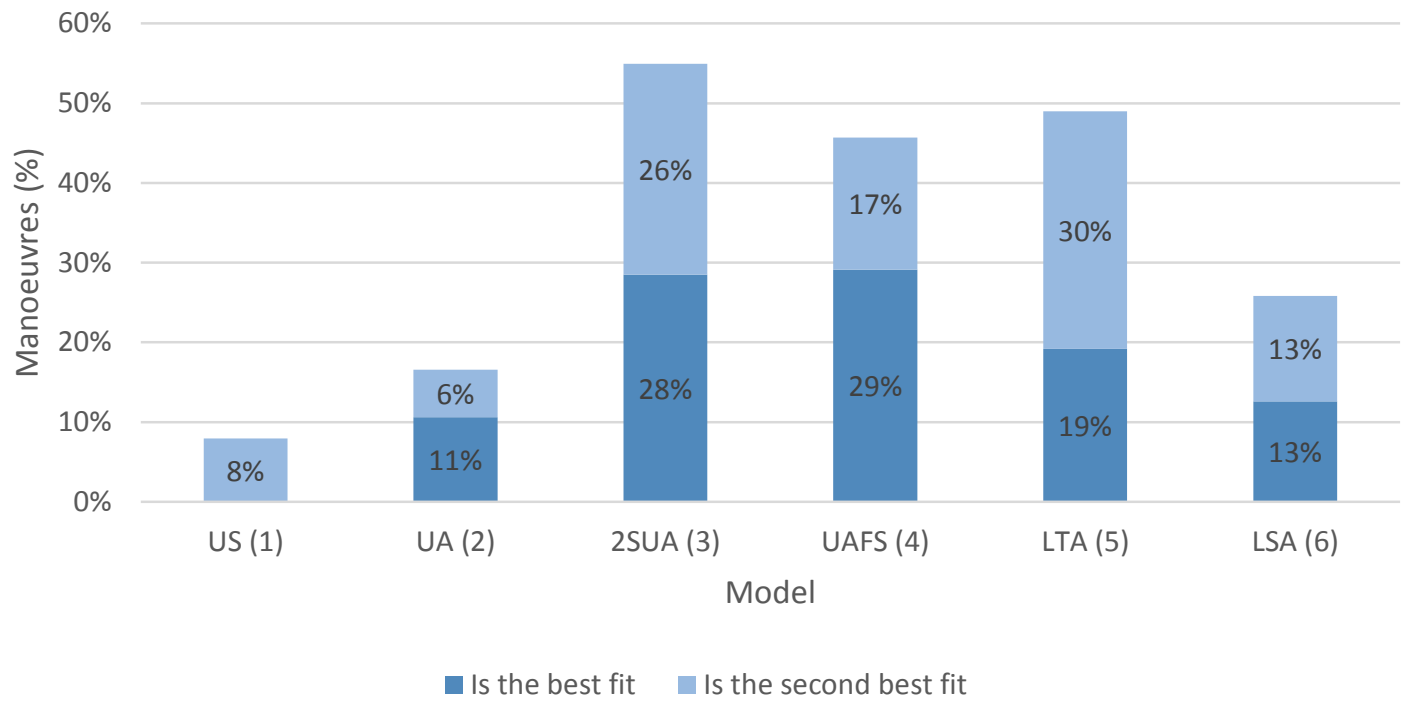

Figure 4. Best fit model

377 For each case, the estimated acceleration values were checked, in order to proof if the calibration 378 resulted in abnormal values. Reference maximum acceleration rates were Rakha et al. [33], 379 Sparks et al. [14], and Liebermann [13]; reference deceleration rates were Fitzpatrick et al. [34]. 380 These reference values determined whether an acceleration value exceed the reasonable rates or not. Figure 5 shows the range of reasonable acceleration rates, as well as the estimated values for each model, depending on the overtaking vehicle speed. Acceleration rates among lower and upper thresholds were considered as valid. Otherwise, they were discarded. 


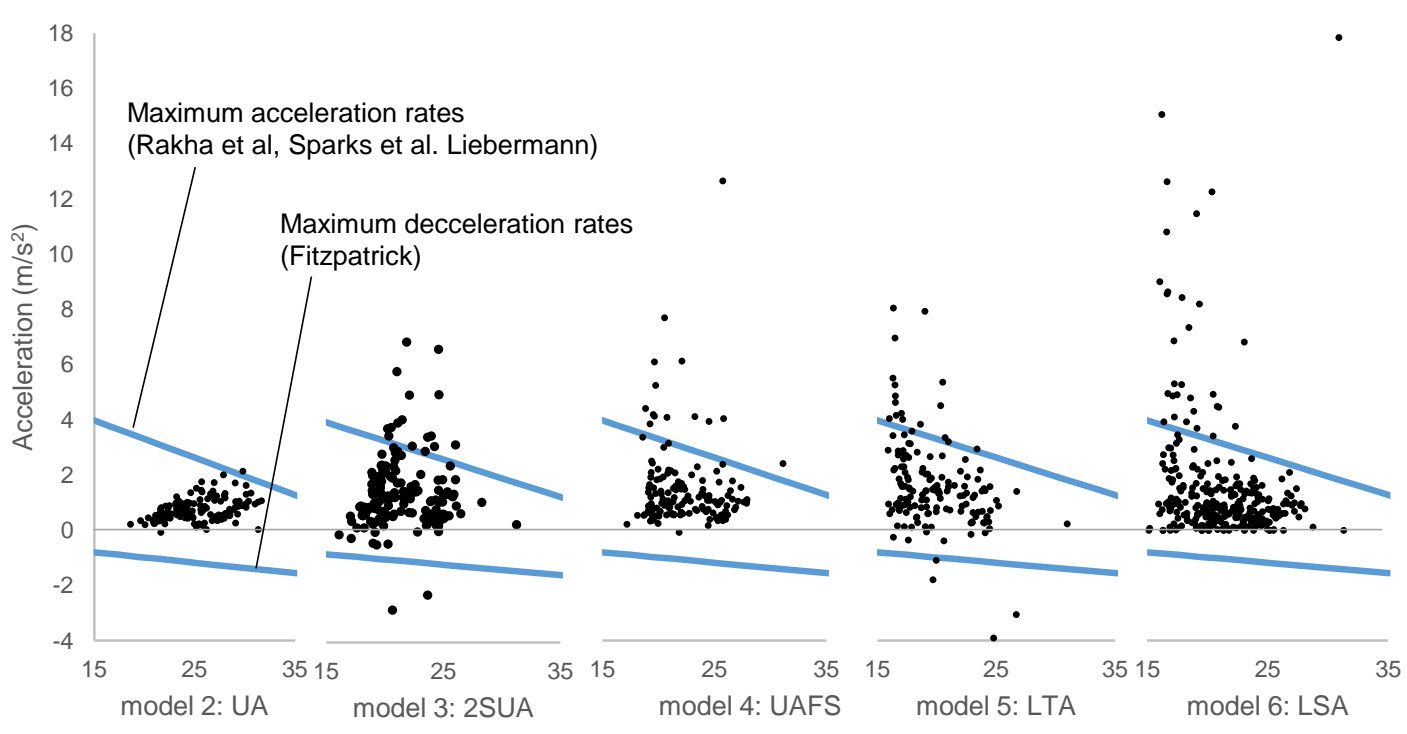

Overtaking vehicle speed $(\mathrm{m} / \mathrm{s})$

Figure 5. Acceleration (positive values) and deceleration (negative values) rate thresholds vs. estimated values

By increasing model complexity, some observed manoeuvres provided non-feasible solutions, as can be seen in Figure 6 . Those manoeuvres were discarded when analysing parameter distributions of Table 4. Models with a high number of discarded manoeuvres could not be able to explain overtaking vehicle behaviour. This case could be associated to overfitting, since the models represented very well the three data points but not properly the rest of the trajectory.

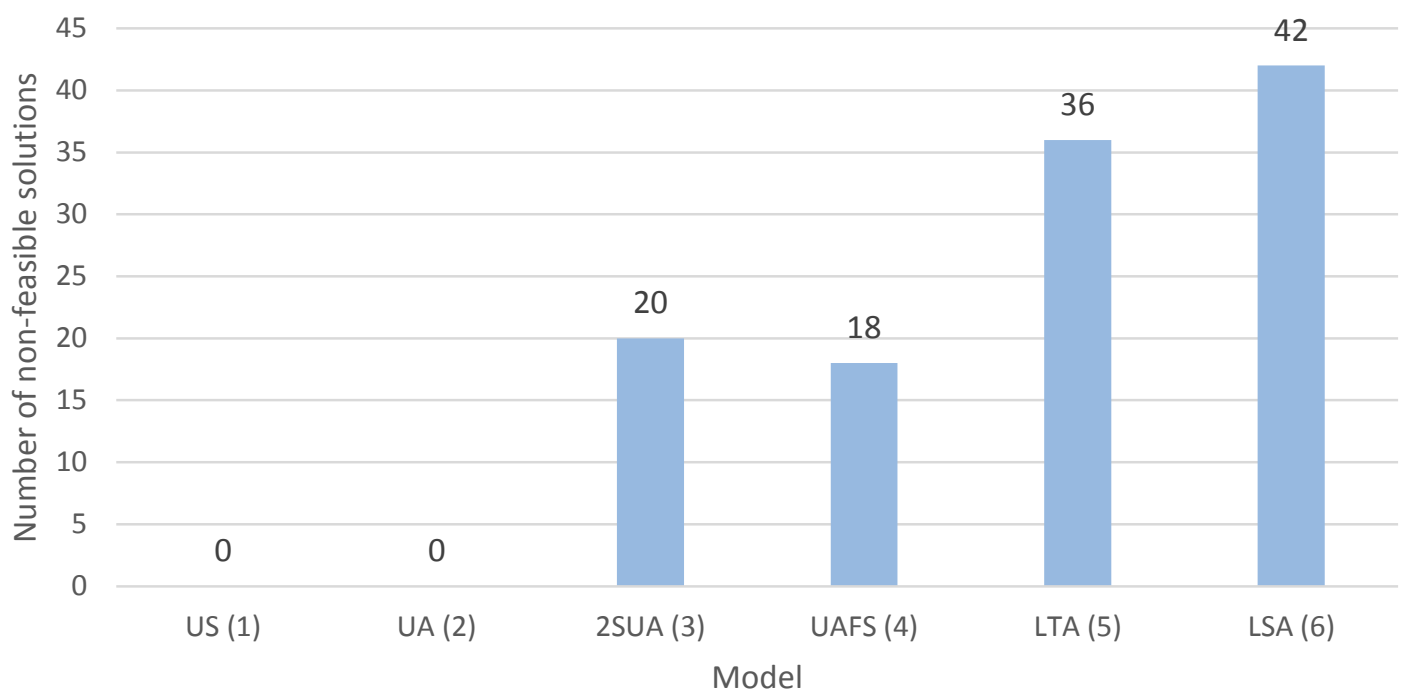

Figure 6. Non-feasible solutions for each model

\subsubsection{Flying manoeuvres}

Flying overtaking manoeuvres represented a different behaviour, compared to accelerative passes. OSD requirements are usually lower for flying passes so they are not considered in many manoeuvre models [6]-[8]. Flying passes do not involve necessarily an acceleration process, because overtaking vehicle speed is higher once the manoeuvre has started. 
Only one model was calibrated for the flying manoeuvres observed using the experimental methodology. It was the model 1 (US), corresponding to an overtaking vehicle travelling at a uniform speed. This selection was made due to the two following reasons:

- According to the definition of flying manoeuvre, the overtaking vehicle neither brakes nor accelerates, accepting an overtaking gap just after reaching the impeding vehicle.

- Overtaking vehicle trajectory measurement was more difficult in flying manoeuvres than in accelerative, since headways $h 1$ and $h 3$ were longer. In most cases, it was not possible to measure the overtaking vehicle speed at $t 1$ and $t 3$. Therefore, it was impossible to calibrate more complex models.

The calibration of this model was based on data from 29 manoeuvres observed with the instrumented vehicle. Despite headways $h 1$ and $h 3$ could not be measured using the laser rangefinders, they were estimated from video images. This estimation was based on drawing reference lines on video frames at known distances, as proposed previously by Carlson et al [22] Those reference points were measured and recorded on video images before starting data collection. Accuracy of those measurements was lower, and it was not possible to calculate reliable instant speeds at $t 1$ or $t 3$.

The model 1 was calibrated minimizing the error of the distances $d 12$ and $d 13$, using the same procedure as for accelerative overtaking manoeuvres. Percent RMSE was $5 \%$ for both $d 12$ and d13 distances. Table 5 shows the distribution of adjusted parameters.

\begin{tabular}{ccc} 
Model & Adjusted parameters & Distribution \& Values (mean \pm SD) \\
\hline 1 Uniform speed & $V p m 13 / \mathrm{Vi}$ & Normal $(1.43 \pm 0.10)$ \\
\hline Table 5. Parameters of overtaking model for flying manoeuvres.
\end{tabular}

\section{Results}

The results of the calibration showed that the use of different models involved significant differences in the estimation of overtaking vehicle trajectories.

Simpler models, such as model 1 (US) were not able to explain the speed evolution during the left lane occupation, in the case of accelerative manoeuvre. The RMSE of this model was over $10 \%$ in initial and final speeds, and of 8 and $4 \%$ in distance $d 13$ and $d 12$, respectively. According to the model calibration, the average speed of the overtaking vehicle would be a $20 \%$ higher than the impeding vehicle speed.

Models 2 (UA), 3 (2SUA) and 4 (UAFS) were more adequate (in terms of RMSE) to estimate both $d 13$ and $d 12$, as well as initial and final speeds $V p 1$ and Vp3. Model 2 (UA) explained the manoeuvre with a uniform acceleration movement during t13. Model 3 (2SUA) incorporated two stages with different acceleration rates, in order to represent the potential change in the acceleration rate once the abreast position was reached. Model 4 (UAFS) was similar to model 3, although it assumed, based on previous research studies, that the overtaking vehicle accelerated until a final speed was reached, keeping this speed after that. The models 2, 3 and 4 presented a low percent RMSE for the calibration variables, being always under $5 \%$.

Model 5 (LTA) incorporated an additional term to represent a linear variation of the acceleration rate as a function of time. Model 6 (LSA) was based also in a linear variation, but as a function of the speed, according to Rakha et al. [33] acceleration profiles. The most complex models were not adequate to represent the entire observed data. The models 5 and 6 calibration process had as a result a relative high number of not feasible solutions, characterized by excessively high (or low) acceleration rates.

In models 2 to 6 , the initial speed of the overtaking vehicle $V p 1$ was, on average, between a $7 \%$ and $10 \%$ higher than the impeding vehicle speed, which revealed that an initial acceleration was performed before starting the overtaking manoeuvre. After this point, the different models showed different acceleration rates. The model 2 (UA) was characterized a mean uniform acceleration of 
$0.77 \mathrm{~m} / \mathrm{s}^{2}$. The model 3 (2SUA) defines two stages: before the abreast position, the mean acceleration rate was $1.18 \mathrm{~m} / \mathrm{s}^{2}$, while after this point it decreased until $0.40 \mathrm{~m} / \mathrm{s}^{2}$. The model 4 (UAFS) showed an equivalent result, being the mean acceleration rate of 1.3 until the time $t f$, when it became zero. The mean time tf was 0.75 times $\mathrm{t} 13$.

According to model 5 (LTA), an average behaviour was characterized an acceleration rate starting at $1.15 \mathrm{~m} / \mathrm{s}^{2}$ and decreasing $0.13 \mathrm{~m} / \mathrm{s}^{2}$ per second. The model 6 (LSA) explains the average behaviour by an acceleration rate following the relationship $a=5.13-0.19 v(v$ in $\mathrm{m} / \mathrm{s}$ and $a$ in $\left.\mathrm{m} / \mathrm{s}^{2}\right)$.

A general conclusion is that an average behaviour of overtaking drivers could be modelled by a decreasing acceleration rate during the overtaking time $t 13$. The reason behind this could be, firstly, that maximum acceleration capacity decreased when speed increases, and second, that drivers might reduce their acceleration rate as far as they observe that the manoeuvre can be completed with safety.

On the other hand, the model 1 (US) was able to explain how a flying manoeuvre was performed. In this case, it had a percent RMSE under $5 \%$ in both $d 12$ and $d 13$.

\section{Discussion}

This research study have compared previously existing overtaking models with observational data of overtaking manoeuvres on a sample of two-lane rural roads in the surrounding of Valencia (Spain). Validity of results should be initially limited to this geographical area, as drivers' behaviour may be different in other regions or countries. Model 1 (US) was equivalent to the previous AASHTO Green Book model [6]. This model could not account for the overtaking vehicle speed variation in accelerative overtaking manoeuvres, since only a uniform speed was considered.

Model 2 (UA) was equal to the one proposed by Rocci [11]. This author proposed an acceleration value ranging between 0.27 and $2.17 \mathrm{~m} / \mathrm{s}^{2}$, with a 50 th percentile of $1.11 \mathrm{~m} / \mathrm{s}^{2}$. These values are slightly higher than the observed distribution. Besides, Rocci assumed that the initial speed of overtaking vehicle was equal to the impeding vehicle speed. This was not observed in the present study data.

Model 4 (UAFS) is similar to Glennon [7] and Hassan et al. [8] although those authors proposed that the overtaking vehicle speed was uniform after the critical point. The model in the present paper was calibrated assuming that the uniform speed started at a certain point (calibrated as well) during the overtaking manoeuvre, since it is not possible to measure the critical point on the field (with any type of equipment). Besides, the uniform speed, among all the other parameters including the final point of the acceleration phase, were assumed to be random variables. The results of the calibration showed that, in contrast to Glennon and Hassan et al. models, the overtaking vehicle speed at the starting point of the manoeuvre was not equal to the impeding vehicle speed. Moreover, the final speed was a random variable $10 \mathrm{~km} / \mathrm{h}$ (on average) over the design speed of the observed roads.

In relation to the acceleration rates, the AASHTO [6] model proposed similar mean values (around $0.62 \mathrm{~m} / \mathrm{s}^{2}$ ) to those obtained from model 2 (UA) (50th percentile at $0.70 \mathrm{~m} / \mathrm{s}^{2}$ ). The AASHTO model defined the acceleration stage before entering the left lane, though. If extreme acceleration rates are analysed, the 85th percentile obtained from Model $2\left(2.25 \mathrm{~m} / \mathrm{s}^{2}\right)$ was close to those observed by Rakha et al. [33] and to those proposed by Sparks et al. [14] at the equivalent speed levels (shown in Figure 5). Similarly Basilio et al. [3] assumed a uniform acceleration model as upper threshold for the driving simulator vehicles. The value of maximum acceleration for the lower speed vehicle $(100 \mathrm{~km} / \mathrm{h})$ was close to the $85^{\text {th }}$ percentile of observations $\left(2 \mathrm{~m} / \mathrm{s}^{2}\right)$. 


\section{Conclusion}

The characterization of the trajectory of overtaking vehicles travelling on the opposing lane is fundamental to calculate the left lane occupation time; which is the main variable used to calibrate and further develop of ADAS, as well as to improve geometric design and marking guidelines for two-lane rural roads. The values of overtaking time provide the sight distance requirements to perform a safe and comfortable manoeuvre, taking into account the opposing flow.

This research characterized the trajectory of 180 overtaking vehicles by using kinematic models, which were calibrated from observations of the real phenomenon. The main conclusions were:

- Accelerative overtaking manoeuvres should be represented by a model that considers acceleration during the left lane occupation phase. A uniform acceleration model with an average rate of $0.77 \mathrm{~m} / \mathrm{s}^{2}$ is recommended for them, balancing accuracy and simplicity. The acceleration rate is log-normal distributed.

- Flying overtaking manoeuvres are adequately represented by a uniform speed model. The speed on left lane is normal distributed, centred on an average value of 1.43 times of the speed of the impeding vehicle.

The ability of these models to predict the manoeuvre duration, travelled distance and abreast position was assessed. However, the extrapolation of this results should be taken with caution, since drivers' behaviour may be different in other geographical areas. The application of the results to overtaking manoeuvres when the overtaken vehicle is a truck should be verified by additional observations.

Despite the above mentioned limitations, the development of ADAS should combine the results of this paper, as a model to predict overtaking vehicle trajectories, with the maximum capacities of the vehicles (acceleration) as well as the input of the current conditions (mainly the distance and speed of the opposing vehicle).

The selection of the best model would depend on its intended applications. Potential applications are the review of road design and marking guidelines, the calibration of traffic microsimulation models and the development or calibration of assistance systems, either based on autonomous driving controllers, or warning devices or mapping and geographical information systems.

\section{Acknowledgments}

Part of this research was included in the project "Desarrollo de modelos de distancias de visibilidad de adelantamiento", with reference code TRA2010-21736 and subsidized by the Spanish Ministery of Economy and Competitivity. Authors would also like to thank Prof. Dr. Sayed, from University of British Columbia, for his valuable review.

\section{References}

[1] A. Molinero, E. Carter, C. Naing, M. Simon, and T. Hermintte, "Accident causation and pre-accidental driving situations. Part 1. Overview and general statistics, TRACE - Traffic Accident Causation in Europe Report," 2008.

[2] R. Gray and D. M. Regan, "Perceptual processes used by drivers during overtaking in a driving simulator.," Human factors, vol. 47, no. 2, pp. 394-417, 2005.

[3] N. Basilio, a. H. P. Morice, G. Marti, and G. Montagne, "High- and Low-Order Overtaking- 
Ability Affordances: Drivers Rely on the Maximum Velocity and Acceleration of Their Cars to Perform Overtaking Maneuvers," Human factors, vol. 57, no. 5, pp. 879-894, 2015.

[4] A. H. P. Morice, G. J. Diaz, B. R. Fajen, N. Basilio, and G. Montagne, "An AffordanceBased Approach to Visually Guided Overtaking," Ecological Psychology, vol. 27, no. 1, pp. 1-25, 2015.

[5] H. Farah, S. Bekhor, and A. Polus, "Risk evaluation by modeling of passing behavior on two-lane rural highways.," Accident; analysis and prevention, vol. 41, no. 4, pp. 887-94, Jul. 2009.

[6] American Association of State Highway and Transportation Official, A Policy on Geometric Design of Highways and Streets, 5th Edition. 2004.

[7] J. C. Glennon, "New and improved model of passing sight distance on two-lane highways," Transportation Research Record: Journal of the Transportation Research Board, no. 1195, pp. 132-137, 1988.

[8] Y. Hassan, S. M. Easa, and A. O. A. El Halim, "Passing sight distance on two-lane highways: Review and revision," Transportation Research Part A: Policy and Practice, vol. 30, no. 6, pp. 453-467, Nov. 1996.

[9] Federal Highway Administration, Manual on Uniform Traffic Control Devices. 2009.

[10] American Association of State Highway and Transportation Official, A Policy on Geometric Design of Highways and Streets, 6th Edition. 2011.

[11] S. Rocci, "A system for no passing zones signing and marking setup," in Transportation Research Board Circular, 1998.

[12] Y. Wang and M. P. Cartmell, "New model for passing sight distance on two-lane highways," Journal of Transportation Engineering, vol. 124, no. 6, pp. 536-544, 1998.

[13] E. B. Lieberman, "Model for Calulculating Safe Passing Distances on Two-Lane Rural Roads," Transportation Research Record: Journal of the Transportation Research Board, vol. 1280, pp. 70-76, 1982.

[14] B. G. A. Sparks, R. D. Neudorf, J. B. L. Robinson, and D. Good, "Effect Of Vehicle Length On Passing Operations," Journal of Transportation Engineering, vol. 119, no. 2, 1993.

[15] P. F. Hanley and D. J. Forkenbrock, "Safety of passing longer combination vehicles on two-lane highways," Transportation Research Part A: Policy and Practice, vol. 39, no. 1, pp. 1-15, Jan. 2005.

[16] J. El Khoury and A. G. Hobeika, "Integrated Stochastic Approach for Risk and Service Estimation : Passing Sight Distance Application," Journal of Transportation Engineering, pp. 571-579, 2012. 
[17] S. El-bassiouni and T. Sayed, "Design Requirements for Passing Sight Distance : A Riskbased Approach," in 90th Transportation Research Board Annual Meeting, 2010.

[18] J. M. Jenkins and L. R. Rilett, "Application of distributed traffic simulation for passing behavior study," in Transportation Research Record, 2004, no. 1899, pp. 11-18.

[19] H. Rakha, K. Ahn, and A. Trani, "Development of VT-Micro model for estimating hot stabilized light duty vehicle and truck emissions," Transportation Research Part D: Transport and Environment, vol. 9, no. 1, pp. 49-74, Jan. 2004.

[20] A. Polus, M. Livneh, and B. Frischer, "Evaluation of the Passing Process on Two-Lane Rural Highways," Transportation Research Record: Journal of the Transportation Research Board, vol. 1701, pp. 53-60, 2000.

[21] D. W. Harwood, D. K. Gilmore, and K. R. Richard, "Passing Sight Distance Criteria for Roadway Design and Marking," Transportation Research Record: Journal of the Transportation Research Board, vol. 2195, pp. 36-46, 2010.

[22] P. Carlson, J. Miles, and P. Johnson, "Daytime High-Speed Passing Maneuvers Observed on Rural Two-Lane, Two-Way Highway: Findings and Implications," Transportation Research Record, vol. 1961, no. 1, pp. 9-15, Jan. 2006.

[23] G. Hegeman, Assited Overtaking, An Assessment of Overtaking on Two-Lane Rural Roads. PhD Thesis. TU Delft, 2008.

[24] G. Hegeman, A. Tapani, and S. Hoogendoorn, "Overtaking assistant assessment using traffic simulation," Transportation Research Part C: Emerging Technologies, vol. 17, no. 6, pp. 617-630, Dec. 2009.

[25] V. Milanés, D. F. Llorca, J. Villagrá, J. Pérez, C. Fernández, I. Parra, C. González, and M. A. Sotelo, "Intelligent automatic overtaking system using vision for vehicle detection," Expert Systems with Applications, vol. 39, no. 3, pp. 3362-3373, Feb. 2012.

[26] R. Isermann, R. Mannale, and K. Schmitt, "Collision-avoidance systems PRORETA: Situation analysis and intervention control," Control Engineering Practice, vol. 20, pp. 1236-1246, 2012.

[27] P. Petrov and F. Nashashibi, "Modeling and nonlinear adaptive control for autonomous vehicle overtaking," IEEE Transactions on Intelligent Transportation Systems, vol. 15, no. 4, pp. 1643-1656, 2014.

[28] J. Loewenau, K. Gresser, and D. Wisselmann, "Dynamic Pass Prediction - A New Driver Assistance System," in Advanced Microsystems for Automotive Applications, Springer, Ed. 2006, pp. 67-77.

[29] C. Llorca and A. García, "Evaluation of Passing Process on Two-Lane Rural Highways in Spain with New Methodology Based on Video Data," Transportation Research Record: Journal of the Transportation Research Board, vol. 2262, no. -1, pp. 42-51, Dec. 2011. 
[30] C. Llorca, A. T. Moreno, A. García, and A. M. Pérez-Zuriaga, "Daytime and Nighttime Passing Maneuvers on a Two-Lane Rural Road in Spain," Transportation Research Record: Journal of the Transportation Research Board, vol. 2358, no. -1, pp. 3-11, Dec. 2013.

[31] C. Llorca, A. García, A. T. Moreno, and A. M. Pérez-Zuriaga, "Influence of age, gender and delay on overtaking dynamics," IET Intelligent Transport Systems, vol. 7, no. 2, pp. 174-181, Jun. 2013.

[32] J. El Khoury and A. Hobeika, "Incorporating Uncertainty into the Estimation of the Passing Sight Distance Requirements," Computer-Aided Civil and Infrastructure Engineering, vol. 22, no. 5, pp. 347-357, Jul. 2007.

[33] H. Rakha, M. Snare, and F. Dion, "Vehicle Dynamics Model for Estimating Maximum LightDuty Vehicle Acceleration Levels," Transportation Research Record, vol. 1883, no. 1, pp. 40-49, Jan. 2004.

[34] K. Fitzpatrick, S. T. Chrysler, and M. Brewer, "Deceleration Lengths for Exit Terminals," Journal of Transportation Engineering, no. June, pp. 768-775, 2012. 